\title{
Erratum to: Understanding appraisal processes underlying the thentest: a mixed methods investigation
}

\author{
Carolyn E. Schwartz • Bruce D. Rapkin
}

Published online: 6 July 2013

(C) Springer Science+Business Media Dordrecht 2013

Erratum to: Qual Life Res (2012) 21:381-388

DOI 10.1007/s11136-011-0023-4

The second author's middle initial was incorrect in the original publication. It is corrected in this erratum.

The online version of the original article can be found under doi:10.1007/s11136-011-0023-4.

C. E. Schwartz ( $\square)$

DeltaQuest Foundation, Inc., 31 Mitchell Road,

Concord, MA 01742, USA

e-mail: carolyn.schwartz@deltaquest.org

C. E. Schwartz

Departments of Medicine and Orthopaedic Surgery,

Tufts University Medical School, Boston, MA, USA

B. D. Rapkin

Department of Epidemiology and Population Health,

Division of Community Collaboration and Implementation

Science, Albert Einstein College of Medicine, Bronx, NY, USA 